\title{
Treatment of toxic epidermal necrolysis with immunoglobulins in a burn center
}

\author{
L Cachafeiro Fuciños ${ }^{*}$ A Agrifloglio, E Herrero de Lucas, MJ Asensio, M Sanchez Sanchez, A García de Lorenzo, \\ IdiPaz
}

From ESICM LIVES 2015

Berlin, Germany. 3-7 October 2015

\section{Introduction}

Toxic epidermal necrolysis is a serious infrequent skin disease, usually secondary to drug. It is associated with high morbidity and mortality, hence the importance of early detection and appropriate treatment, although currently the most effective treatment remains controversial.

\section{Objectives}

The aim of our study was to evaluate the efficacy of immunoglobulin therapy in patients admitted in a Critical Burn Unit with SJS / TEN.

\section{Methods}

A prospective study has been developed, it included all patients over 16 years old with diagnosis of StevensJohnson Syndrome (SJS) and Toxic Epidermal Necrolysis (TEN) that were admitted to the Burns Critical Unit from Hospital Universitario La Paz, since June 2007 until June 2014. A protocol with a multidisciplinary team was established. The diagnosis was confirmed by biopsy and all of them were treated with immunoglobulins $0.75 \mathrm{~g} / \mathrm{kg} / \mathrm{dx}$ 4 days ( \pm 200 grams). Date collected were demographic data, the surface of epidermal detachment, causative drug, SCORTEN, length of stay, complications and mortality.

\section{Results}

During this period 24 patients were admitted in our unit, 2 with a diagnosis of SJS, 2 with SJS-TEN overlap, and 20 with TEN. Mean age was $51 \pm 13$ (16-89). 17 patients (71\%) were men. The average stay was $11 \pm 5$ days (2-90). The average surface of epidermal detachment was $70 \%$, but 13 patients had affected more than $90 \%$. SCORTEN at $24 \mathrm{~h}$ and $72 \mathrm{~h}$ was 3 . The mortality was $25 \%$ (six patients),

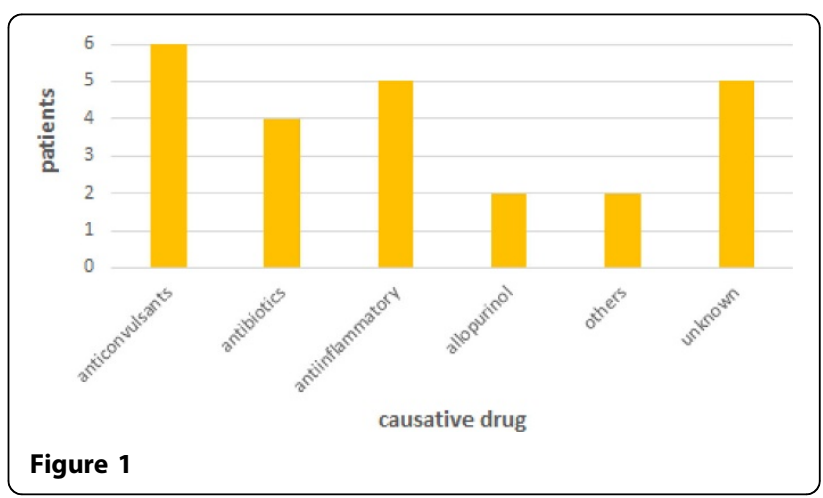

and the complications that we found were distributive shock, ARDS and renal failure requiring CVVHDF.

\section{Conclusions}

In our study we have seen that the mortality of our patients is lower than expected based on the SCORTEN score (25\% vs $35.3 \%$ ). Immunoglobulins could be a good option to treat Toxic Epidermical Necrolysis, considering they are critical ill patients, with a large body surface area affected and with a high morbi-mortality. Although a multicenter and randomized study is necessary to establish the best treatment for SSJ/TEN.

Published: 1 October 2015

\section{References}

1. Huang YC, Li YC, Chen TJ: The efficacy of intravenous immunoglobulin for the treatment of toxic epidermal necrolysis: a systematic review and meta-analysis. Br J Dermatol 2012, 167(2):424-432.

2. Aires DJ, Fraga G, Korentager R, Richie CP, Aggarwal S, Wick J, et al: Early treatment with nonsucrose intravenous immunoglobulin in a burn unit reduces toxic epidermal necrolysis mortality. J Drugs Dermatol 2013, 12(6):679-684. 
3. Wang J, McQuilten ZK, Wood EM, Aubron C: Intravenous immunoglobulin in critically ill adults: When and what is the evidence? J Crit Care 2015, 30(3):652.e9-16.

doi:10.1186/2197-425X-3-S1-A493

Cite this article as: Cachafeiro Fuciños et al:: Treatment of toxic

epidermal necrolysis with immunoglobulins in a burn center. Intensive

Care Medicine Experimental 2015 3(Suppl 1):A493.

\section{Submit your manuscript to a SpringerOpen ${ }^{\mathcal{O}}$ journal and benefit from:}

- Convenient online submission

- Rigorous peer review

- Immediate publication on acceptance

- Open access: articles freely available online

- High visibility within the field

- Retaining the copyright to your article

Submit your next manuscript at $>$ springeropen.com 